\title{
The Research of Training Mode for New Employees of Aircraft Maintenance
}

\author{
Zhou JIANG*, Bin-Bin REN, ji SONG, Qing-Qing GUO \\ Sanya Aviation \&Tourism College Sanya, Hainan, China \\ "Email: valnut@qq.com \\ http://www.hnasatc.com/gb/
}

Keywords: Aviation maintenance, Maintenance staff, Training mode.

\begin{abstract}
With the rapid development of Chinese economy, the number of the civil aircraft increase steadily, more and more maintenance staff will be needed, it will challenge the training mode of maintenance staff. Guided by training theories, this paper will try to investigate the training situation of the maintenance staff. It will collect the relevant investigation data with the help of methods and try to find out the problem existing in the maintenance training work at the present stage. At the same time, it will propose a training mode.
\end{abstract}

\section{Introduction}

\section{Background}

In the 21st century, the competition between enterprise and enterprise are talented person's competition, aircraft maintenance units and related enterprises are no exception. Under the background of fierce competition in the market, if you want to survive in the competition, it must pay attention to the cultivation of talents, especially need to strengthen the staff training in schedule and line maintenance [1].

The civil aviation maintenance system resources analysis report shows that the registered number of civil aviation transport aircraft of China has reached 1732 by the end of 2011. With rising rate of 100-150 aircraft in a year, it will require an increase of 4800-7200 maintenance staff a year. Actual demand may be bigger in consideration of personnel loss. [2] in recent years, the demand of civil aviation maintenance enterprise is huge. The change of the number in domestic transport aircraft and the change of the number in domestic maintenance staff are shown in the figure below.

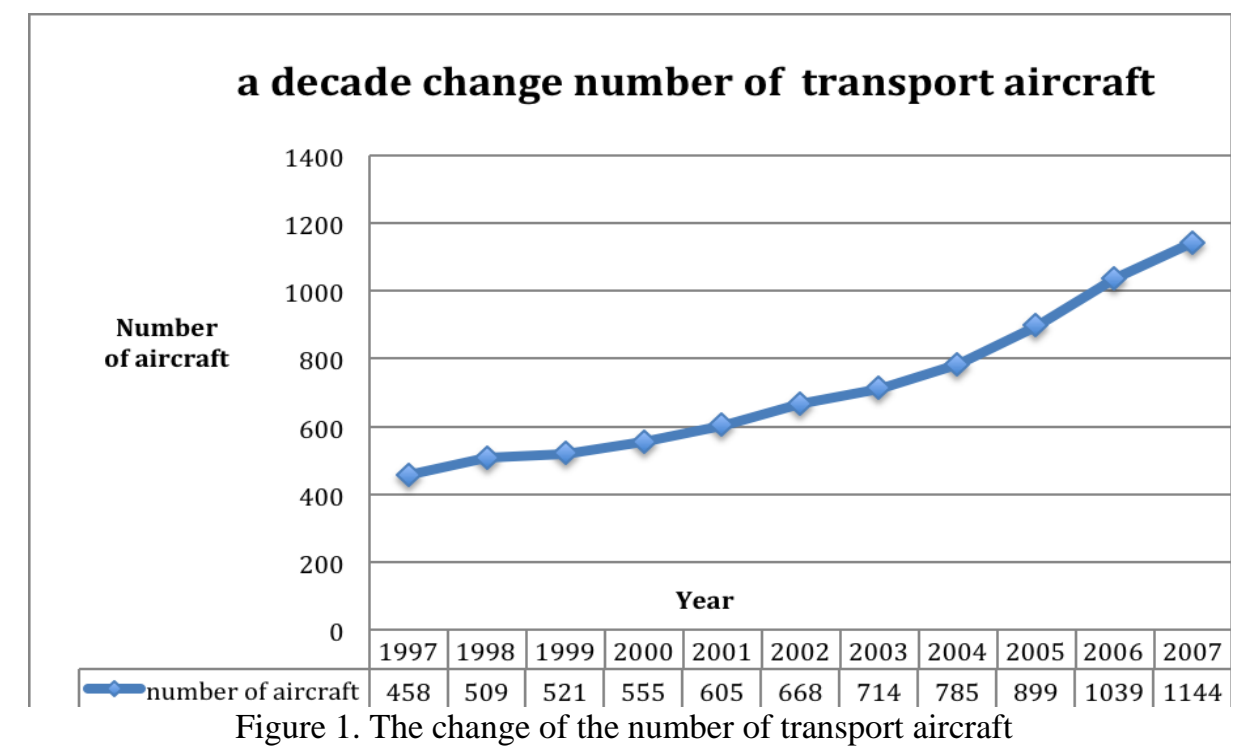

As shown in figure 1-1. At the end of 2007, the number of registered transport aircraft in China has reached 1144 . The Chinese civil aviation maintenance system resources analysis report shows that it has reached to 1732 at the end of 2011 . The average growth rate is $11.04 \%$ in a year. 


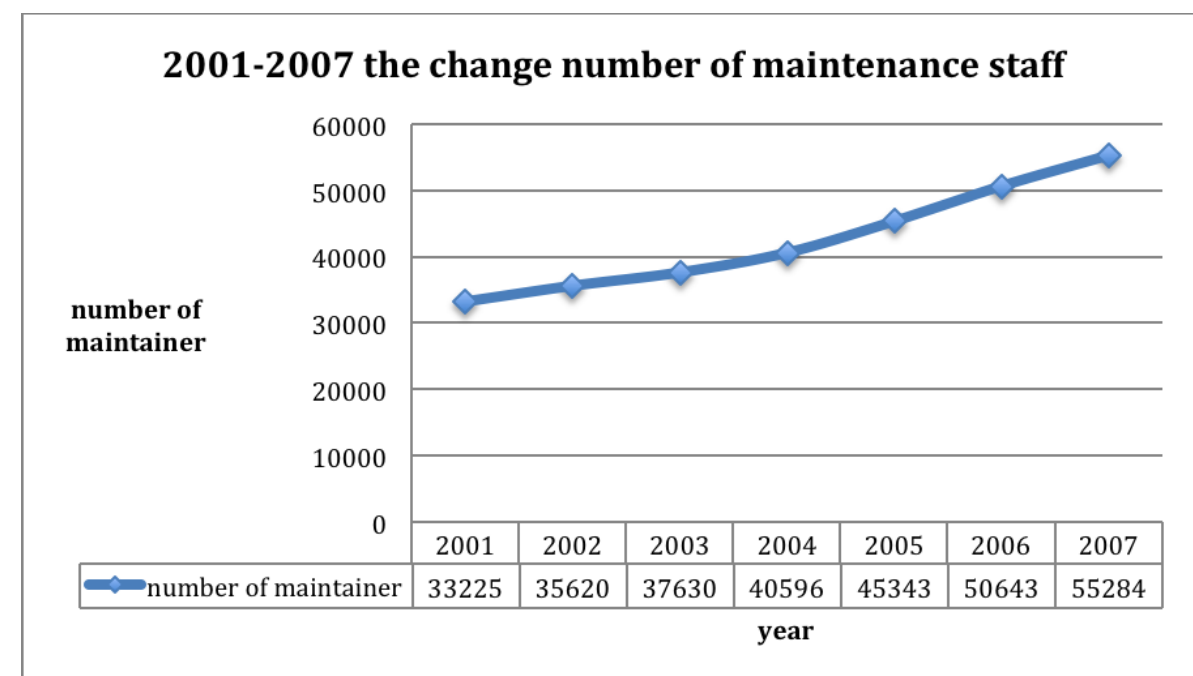

Figure 2. 2001-2007 the change number of maintenance staff

As shown in figure 1-2.At the end of 2007, the number of maintenance staff was about 55284 . The Chinese civil aviation maintenance system resources analysis report shows that it reached to 67000 at the end of 2011. The average growth rate is $8.8 \%$ in a year.

The above data shows that the growth rate of maintenance personnel is behind the growth rate of the aircraft. at the present stage, human resources of civil aviation maintenance is not enough, maintenance units must improve training system, it will ensure that each new maintenance staff can timely accept and engage corresponding systematic training.

\section{Characteristics of Maintenance Training for New Employees}

Maintenance work need higher personnel's technical requirements .it will take long time for training new employees to obtain the corresponding qualifications. mature maintenance staff need a training cycle of 6 years in consideration of working efficiency, experience and the comprehensive ability[3.4]. The characteristics of specific training as follows:

long training cycle

wide training content

strong practical training

high training cost

\section{Training Status of New Employee in the X Airline}

In order to understand the existing training status, it will adopt sampling questionnaire, sampling case analysis to investigate 80 maintenance staff in $\mathrm{X}$ airline. 80 questionnaires were valid, 30 incident cases were analyzed in $\mathrm{X}$ airline.

\section{Questionnaire Investigation}

Table1. This is the project of this questionnaire

\begin{tabular}{|c|c|}
\hline \multicolumn{2}{|c|}{ Employee training questionnaire } \\
\hline Work years & \\
\hline Training time & very reasonable () reasonable () general () unreasonable () \\
\hline Training location & very good () good () general () bad () \\
\hline The level of instructor & very good () good () general () bad () \\
\hline Course set & very necessary () necessary () general () unnecessary () \\
\hline Training content & very good () good () general () bad () \\
\hline $\begin{array}{l}\text { Training organization and } \\
\text { management }\end{array}$ & very good () good () general () bad () \\
\hline Training logistics & very good () good () general () bad () \\
\hline Trainees learning attitude & very good () good () general () bad () \\
\hline
\end{tabular}


Working years survey distribution was shown in Figure 3-1, there are 10 persons with more than 8 years' experience in maintenance, accounting for $13 \%$ of the total number; 40 persons with $4-8$ years' experience in maintenance, accounting for $50 \%$ of the total number; 30 persons with $1-3$ years experience in maintenance, accounting for $37 \%$ of the total number.

\section{Case Analysis}

Incident found mainly in the following several aspects through 30 incident in the $\mathrm{X}$ airline. mainly is the knowledge and skills, tool management, environment, personnel fatigue, work task, information communication and other aspects. The cause of the accident statistics are as follows:

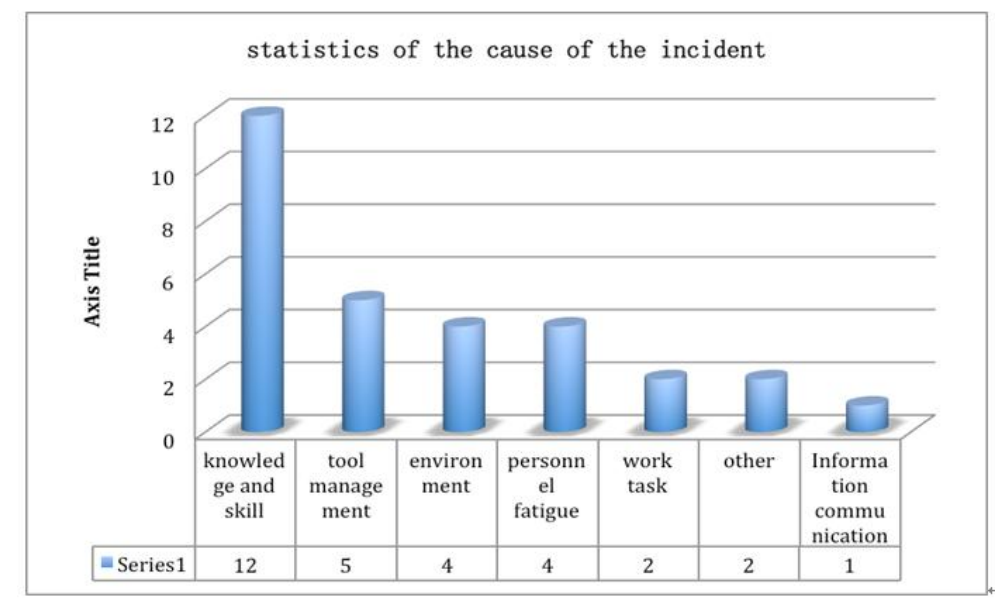

Figure 3. This is the statistics of the incident cause

These incidents seriously affect the safety record of maintenance, the company caused great damage to property. At the same time, the occurrence of these events show that safety management and maintenance personnel training link is still very weak.

The 30 incident involved 36 people. From the point of maintenance experience, 10 people have 8 years of experience in maintenance, accounting for $28 \%$ of the total. 6 people have 5-8 years of experience in maintenance, accounting for $17 \%$ of the total. 20 people have 1-3 years of experience in maintenance, accounting for $55 \%$ of the total. As shown in the figure below.

\section{The Analysis and Reason of Existing Problems in Training}

Training problems in the new employee are as follows $[5,6]$.

\section{Complex New Employees}

New employees include college students, maintenance personnel with aviation background but not engaged in aviation, the terminal staff, airlines or overhaul factory persons, etc. training of using unified form is bad for people to be a good talent.

\section{Training Effect Evaluation Method}

The evaluation method is simple and practical, but it is difficult to reflect the training effect, more difficult to quantify the training input and output efficiency, also easy to make the conflict between employees, and perfunctory to complete the training.

\section{Training Time}

New employee training insisting that shorten the adjustment period, theoretical study and post practice training time was compressed and cause a lot of new employees grasp of the theoretical knowledge is not solid, understand thoroughly, to visit and inspect link is insufficient, lack of practical experience, work often appear mistake, coupled with inadequate understanding of the situation of departments and colleagues, the interaction between new and old employees, often is 
not fully integrated into the department, post work, tension and doubts when no new hires can be eliminated, has affected the new staff enter the work commitment.

\section{Standard PTR Management Mechanism}

$\mathrm{X}$ though airlines has been established the corresponding training in internal management system, but for specific new member PTR appraisal management, and lack of systemic and normative. Due to the imperfect management, easy to cause individual employee training is only perfunctory.

\section{Conclusion}

Aiming at the above problems, combining with some management procedures of the original students and faculty, company establish new employees training mode. it can change PTR training time,Training classification according to the new staff situation and establish rewards and punishments system. It can effectively improve maintenance practical operation skills .maintenance new staff can work independently through examination.

In this paper, with the help of the questionnaire, case analysis in $\mathrm{X}$ airline, It collected relevant investigation data and found out the problem existing in the maintenance training work. Training model should be established they should build a practice training records system to train new maintenance staff. It will motivate maintenance personnel to participate in all kinds of training work. It will make the maintenance personnel master necessary theories and skills. It will help maintenance personnel develop career path and improve the enthusiasm of the maintenance personnel for aircraft maintenance work. At the same time, it will improve work efficiency.

\section{Acknowledgments}

I would like to express my gratitude to all those who helped me during the writing of this thesis. Firstly, I would like to thank Hainan province college education reform search program .secondly ,I'd like to thank AIRBUS support's EU-CHINA cooperation project for providing me the opportunity to study .Also I would like to give my special thanks to Feng Yingjin , it's him, who give me suggest, That will be benefit for my future work.

\section{References}

[1].Sun Jing, XIE JING YING. Aviation maintenance personnel training problem analysis[J], Corporate Culture. 2012(5): 245

[2]. Wang Fu Sheng, Han ke. An exploration on the training for maintenance personnel[R]. maintenance engineering of China southern airlines CO.LTD.2010.

[3]. Wang qun. Extraction "training does not reach the designated position"[M], Anhui Maintenance Department in Eastern Airlines Aircraft Maintenance Engineering CO.LTD. 2010

[4].Zhu Xingdong, Huang Kui, Wang Zheng. Application of Multimedia Technology in Maintaining and Training of Aviation[C]. China Computer Federation. 2001.233-237.

[5].Jiang Huanbing, Wang Zhenwei, Xue Jing, Gao Yun. three D virtual technology in the application of civil aircraft maintenance training[J]. information of science and technology , 2013(12):360-360

[6].Ji Mingang. A study of the industrialization of China Yunnan civil aviation maintenance enterprises[D], Yunnan University. 2010. 